\title{
REVIEW
}

James H. Woods - Gail Winger

\section{Current benzodiazepine issues}

Received: 26 August 1993 / Final version: 18 April 1994

\begin{abstract}
This article deals with some of the recent evidence bearing on the issues of the liability of benzodiazepines to lead to abuse, dependence, and adverse behavioral effects. Reviews of epidemiological, clinical and experimental literature indicated that the previous conclusion about abuse of these drugs still holds: the vast majority of the use of benzodiazepines is appropriate. Problems of nonmedical use arise nearly exclusively among people who abuse other drugs. Nevertheless, there are reasons for concern about patients who take benzodiazepines regularly for long periods of time. These drugs can produce physiological dependence when taken chronicaly, and although this does not appear to result in dose escalation or other evidence of "psychological dependence," physiological dependence can result in patient discomfort if drug use is abruptly discontiniued. Also, physicians are currently prescribing shorter-acting benzodiazepines in preference to longer-acting benzodiazepines. The shorter-acting drugs can produce a more intense withdrawal syndrome following chronic administration. Furthermore, rates of use of benzodiazepines increase with age, and elderly patients are more likely than younger ones to take the drug chronically. The clearest adverse effect of benzodiazepines is impairment of memory. This, too, may be particular concern in older patients whose recall in the absence of drug is typically impaired relative to younger individuals, and who are more compromised following drug administration.
\end{abstract}

Key words Benzodiazepines - Drug abuse · Physiological dependence $\cdot$ Behavioral effects

James H. Woods $(\bowtie) \cdot$ Gail Winger

Department of Pharmacology,

University of Michigan Medical School,

Ann Arbor, MI 48109, USA

This article was supported by USPHS Grant DA-00254 and by funding from Hoffmann-La Roche, Ine.

\section{Introduction}

Benzodiazepines have long been a subject of lively scientific and public interest, and this interest remains intense. Our 1987 review of the liability of benzodiazepines for abuse, dependence, and adverse behavioral effects (Woods et al. 1987, 1988) covered the relevant literature of the previous 25 years, since the drugs were introduced. This substantial literature had remarkably doubled 5 years later, when we reviewed it again (Woods et al. 1992). In brief, both reviews concluded that the vast majority of use of these drugs is appropriate, with no important risk of abuse among the general population or typical patients.

In the present article we wish to draw attention to some key issues of current interest. In preparing this article, we have considered some of the most recent information bearing on these issues; the new data sharpen the picture, but do not alter our basic conclusions. We hope here to provide a perspective on what has been learned and, equally important, what remains to be learned about the ways in which these drugs are now used and the consequences of this use.

In view of the extensive use of benzodiazepines over the past 30 years, epidemiology should logically serve as our primary guide in identifying issues deserving scrutiny. In fact, the literature on the epidemiology of benzodiazepine use is vast, and is distinguished by a very substantial agreement among diverse sources of information about how these drugs are used. One of the most consistent findings continues to be that, while most patients receiving benzodiazepine prescriptions use the drugs only for relatively brief periods, a sizeable minority has used benzodiazepines for long periods of time. In the United States, the annual prevalence of use of benzodiazepine anxiolytics declined from $11.1 \%$ to $8.3 \%$ between 1979 and 1990 . However, one in four users in 1990 had used these drugs regularly for a year or longer; somewhat fewer users of 
benzodiazepine hypnotics (14\%) reported long-term use (Balter 1991). Rates of use increase with age, so that elderly patients account for a disproportionately large percentage of benzodiazepine prescriptions; in the United States in 1991, while those 65 or older represented about $13 \%$ of the population (Golenpaul 1991), they received $27 \%$ of all prescriptions for benzodiazepine tranquilizers and $38 \%$ of prescriptions for benzodiazepine hypnotics (IMS America Ltd. National Disease and Therapeutic Index 1991). Elderly patients are also more likely than younger patients to continue use for long periods. Although characteristics of benzodiazepine users have not changed appreciably in recent years, there has been a dramatic shift in the specific agents used. In many countries, including the United States, use of the longer-acting compounds has been substantially supplanted by increased use of the shorter-acting agents; also, while use of benzodiazepine anxiolytics has declined, use of benzodiazepine hypnotics has remained stable or increased (Woods et al. 1992). These characteristics of the actual use of benzodiazepines help to focus the following discussion of our findings relative to current benzodiazepine issues.

\section{Abuse versus therapeutic use}

Some authors have expressed the view that the great prevalence of use of benzodiazepines must reflect overprescription and relate to the drugs' liability for abuse and dependence; others have attributed it to the prevalence of the disorders for which benzodiazepines are prescribed. Our first review (Woods et al. 1987, 1988) suggested that these divergent views of benzodiazepine use (which we termed the "abuse model" and the "therapeutic use model") arose from studies of two distinct populations. Epidemiologic studies had found that non-medical use of benzodiazepines is rare in the general population, but relatively frequent among populations of drug abusers; these findings paralleled experimental research, which found little or no preference for benzodiazepines among normal or anxious subjects, but some limited reinforcing effects of these drugs among subjects with histories of drug abuse. Other survey data had demonstrated that most actual use of benzodiazepines is appropriate, in that users" in the community do have the disorders for which benzodiazepines are deemed effective. Although clinical research had found that prolonged use of therapeutic doses can lead to physiological dependence, this dependence is not usually accompanied by a tendency to escalate doses or other behaviors characteristic of "psychological dependence" or "addiction." We concluded that the widespread use of benzodiazepines is explained better by the "therapeutic use model" than by the "abuse model".

\section{Recent findings}

Recent epidemiologic studies have lent support to earlier findings, from national household surveys in the United States (Mellinger et al. 1978, 1984a), that actual use of benzodiazepines is generally appropriate. Community surveys in the United States (Swartz et al. 1991) and Western Europe (Fichter et al. 1989; Pakesch et al. 1989; Vazquez-Barquero et al. 1989) have found significant positive correlations between benzodiazepine use and psychiatric disturbance as measured using standard rating instruments. Among patients of general practices, those who had received prescriptions for benzodiazepines scored significantly higher on such ratings than matched controls who had not received such prescriptions (Salinsky and Dore 1987; GenéeBadia et al. 1988) Other studies of general medical patients in the United States (Haskell et al. 1986; Ried et al. 1990) and Western Europe (Magni et al. 1986; Bellantuono et al. 1989; Antonijoan et al. 1990) also showed that benzodiazepine users were distinguished by significant psychiatric morbidity; some of these (Magni et al. 1986; Antonijoan et al. 1990; Ried et al. $1990)$ specifically studied elderly patient populations.

Other recent research has documented continuing declines in non-medical use of benzodiazepines in the general population. Periodic household surveys by the National Institute on Drug Abuse (NIDA) have shown that, between 1985 and 1992, annual rates of non-medical use of tranquilizers decreased by more than half among adolescents (12-17 years), young adults (18-25), and adults (26 and older; National Household Survey on Drug Abuse: Main Findings 1991). In 1992, between $1 \%$ and $3 \%$ of a national sample reported nonmedical use within the previous year, and $0.6 \%$ or less within the previous month (National Household Survey on Drug Abuse: Main Findings 1991; National Household Survey on Drug Abuse: Population Estimates 1992). Annual NIDA surveys of high school seniors and college students found similar declines in non-medical use of tranquilizers over this period (Johnston et al. 1993a,b).

\section{Risk factors for abuse}

These recent data lend further support to the view that most use of benzodiazepines is appropriate, and that these drugs have little liability for abuse in most populations. Nevertheless, as Cooper et al. remarked in this context, "it would be naive to fail to recognize that a minority of those seeking treatment are or will become drug abusers..." (Johnston et al. 1993a). Recent research provides some interesting suggestions about possible risk factors for abuse of benzodiazepines in typical patient populations.

For example, although physiological dependence in itself is not usually accompanied by a tendency to increase dosage or to recreational use, at least one study 
has suggested that abrupt withdrawal from benzodiazepine treatment might increase the tendency to selfadminister the drugs (Cappell et al. 1987). If this finding were replicated, it would raise the possibility that efforts to discontinue benzodiazepine treatment abruptly might lead to inappropriate continued use in dependent patients. The same study, however, also supported current recommendations to discontinue benzodiazepine treatment by gradual tapering, since patients discontinued in this way were significantly less likely to self-administer the drugs.

Perhaps the most intriguing finding of recent experiments in human self-administration of benzodiazepines was that moderate drinkers, i.e. subjects who consumed an average of 11 alcholic drinks weekly, consistently chose to take diazepam rather than placebo after they had learned to differentiate the capsules. This was in marked contrast to earlier studies by the same investigators, in which most normal or anxious subjects showed no preference for diazepam (De Wit et al. 1989). Since moderate drinkers might represent a "bridge" between the normal population and sedative abusers, further studies of these subjects could help to elucidate the characteristics that make some people and not others susceptible to benzodiazepine abuse.

\section{Physiological dependence}

Physiological dependence is a state induced by drug treatment that results in a time-limited withdrawal reaction when treatment is discontinued (or when a benzodiazepine antagonist, such as flumazenil, is administered). One of the issues most frequently discussed in recent literature on benzodiazepines has been the risk that physiological dependence can develop even when the drugs are administered only at doses within the recommended therapeutic range. Although this risk was suspected by about 1980 , and has subsequently been confirmed and to some extent characterized in numerous clinical studies, our understanding of many basic aspects of the phenomenon and of its significance has not advanced appreciably.

\section{Risk factors}

The studies that established the potential of benzodiazepines to produce physiological dependence at therapeutic doses also found that not all patients using these drugs became dependent, i.e. some did not show signs of withdrawal when the drugs were discontinued. More recent studies have supported this finding, although they have not clarified what proportion of users do become dependent nor the determinants of dependence.

The early studies of therapeutic dose dependence generally examined the effects of discontinuation in patients who had used the drugs for relatively long periods, and it was assumed that the risk increased with duration of use; studies in animals supported that view (Woods et al. 1987). However, more recent human studies have demonstrated withdrawal after relatively brief periods of use, e.g. 2 weeks (Orsini et al. 1990); and studies comparing discontinuation after different periods of treatment have found no difference in the incidence of withdrawal (Orsini et al. 1990). Other factors that have been considered as possible determinants of the development of physiological dependence have included drug half-life, magnitude of dose, patients' prior drug use, age, and personality traits; while some of these factors have influenced the development of dependence in animals (Woods et al. 1992), none has yet been shown to be clearly related to the risk of dependence in patients.

In $1990,23 \%$ of US adults who used benzodiazepine hypnotics had used the drugs nightly for at least 4 months (Balter 1991). Since hypnotic prescriptions have increasingly called for the short-acting triazolam, a considerable proportion of chronic hypnotic use now consists of repeated intermittent, rather than continuous, exposure to the agonist. Apart from studies of rebound insomnia, which is a withdrawal phenomenon, there has been no systematic investigation of the liability of this type of therapeutic regimen to produce physiological dependence.

\section{Effects}

Some authors have argued that the risk of physiological dependence is so serious that use of benzodiazepines should be much more strictly limited or curtailed. However, despite the large numbers of long-term users, many of whom may be physiologically dependent on these drugs, we have yet to see persuasive evidence of harm arising from this dependence per se - apart, that is, from the phenomena of withdrawal upon discontinuation. Clinical studies have continued to show that the discomfort of withdrawal can be minimized by gradual tapering of dosage (Busto et al. 1986; Cantopher et al. 1990; Schweizer et al. 1990).

Although it has not been established whether dependence is more or less likely to develop with short versus long half-life benzodiazepines, recent studies have shown that abrupt withdrawal from the short-acting drugs develops more rapidly and may be more intense than withdrawal from benzodiazepines with longer durations of action (Rickels et al. 1988; Schweizer et al. 1990; Noyes et al. 1991). It has also been found that effective discontinuation of short-acting benzodiazepines, to minimize the risk of rebound symptoms and other effects of withdrawal, requires a particularly gradual and prolonged tapering regimen (Mellman and Uhde 1986; Fyer et al. 1987; Pecknold et al. 1988; Noyes et al. 1991) and that, at least in the 
short term, patients discontinued from these drugs are more likely to resume use than are patients discontinued from long-acting agents (Rickels et al. 1990).

In the longer term following discontinuation, the likelihood of continued abstinence does not appear to depend on the type of benzodiazepine used, dosage before discontinuation, nor the intensity of withdrawal phenomena; it is unclear whether the duration of treatment before discontinuation affects subsequent abstinence (Ashton 1987; Golombok et al. 1987; Rickels et al. 1991). Some studies have found that younger patients are more likely than older patients to remain abstinent after discontinuing benzodiazepine treatment. (Ashton 1987; Rickels et al. 1991). This would not appear to be related to the relative severity of withdrawal, however, since withdrawal may actually be less intense among older patients (Schweizer et al. 1989). Another recent finding bearing on discontinuation of benzodiazepines is that, unlike detoxified and abstinent alcoholics, patients discontinued from benzodiazepines express little or no "craving" to resume use of these drugs (Lucki et al. 1991).

\section{Prevention}

Despite concerns about the risk of physiological dependence on benzodiazepines, there has been little consideration of ways in which dependence might be prevented from the onset of treatment. Clinical authorities have long recommended that use should be interrupted by occasional "drug holidays," which would permit reassessment of the need to continue treatment and might also reduce the risk of dependence development. However, the effect of drug-free intervals on the development of dependence has not been studied under controlled conditions. If it can be shown that such intervals actually can prevent or delay the development of dependence, more systematic research will be needed to specify how best to schedule them.

Another possible approach to prevention has been suggested by studies of chronic benzodiazepine treatment in animals; periodic injections of a benzodiazepine antagonist significantly reduced the intensity of the subsequent withdrawal syndrome (Gallager et al. 1986). The suggestion that it might be possible in this way to "reset the clock" for the initiation of dependence needs to be pursued through studies of a variety of benzodiazepines in both animals and humans.

\section{Adverse behavioral effects}

Laboratory studies of the effects of benzodiazepines on various types of psychomotor performance continue to appear in large numbers, and remain disappointing with respect to the consistency of results. The most consistent finding is that single doses of all benzodiazepines tested can be shown to impair some types of performance, though no particular type of performance is affected reliably across studies. While earlier studies indicated that these decrements tended to diminish when doses were repeated, as would be typical of therapeutic use, some recent experiments suggest that some types of impairment may be sustained with chronic dosing; however, results of such studies again are inconsistent, and these findings remain inconclusive. Among the experimental behaviors affected by benzodiazepines are performances in simulated or real automobile driving. However, whether such drug effects actually contribute to driving accidents can be established only by case-controlled epidemiologic studies of drivers involved in accidents; the available evidence is not adequate to the question (Ray 1992; Woods et al. 1992).

The greatest recent advance in our understanding of the psychomotor effects of benzodiazepines comes from increasingly sophisticated research on human recall. It can now be shown reliably that acute doses of these drugs can markedly impair recall, and especially delayed recall (recall of stimuli presented some time earlier, as opposed to immediate recall). With regard to the usual therapeutic condition of repeated dosing, one well-designed experiment (Lucki and Rickels 1988) suggests that chronic users experience impairment of delayed recall during short periods of time following each dose. However, further systematic study is needed to establish whether and to what extent tolerance may develop to any or all of the drugs' amnestic effects Further research is also required to pursue important recent suggestions that benzodiazepines may vary substantially in their effects on recall (Woods et al. 1992).

\section{Elderly patients}

It has been suggested for many years by many authors that elderly patients may be especially sensitive to the effects of benzodiazepines. Certainly this suggestion is well grounded in the pharmacokinetics of aging, and has been reinforced by the epidemiologic demonstration of a greater incidence of adverse CNS reactions in older patients taking these drugs (Greenblatt et al. 1989). However, our review of the literature (Woods et al. 1992) as well as other recent reviews (Gurwitz and Avorn 1991; Ray 1992) concludes that the relationship between age and relative susceptibility to adverse effects from benzodiazepines and other drugs is more complex than previously thought, and remains controversial.

For example, a number of recent epidemiological studies have examined the association between use of benzodiazepines and the risk of falls and/or hip fractures in elderly populations. Some of these studies (Sobel and McCart 1983; Hale et al. 1985; Oster et al. 1987, 1990; Ray et al. 1987, 1989; Cummings et al. 1991; Myers et al. 1991) but not others (Wells et al. 1985; Sorock and Shimkin 1988; Grisso et al. 1991; 
Trewin et al. 1992) have found a significant positive association. However, this research has been helpful in identifying other factors that may increase this risk as much as or more than the benzodiazepines do, including the use of other psychoactive and non-psychoactive drugs as well as medical disorders, especially neurological impairment. In sum, the research suggests that, in some circumstances, benzodiazepines can contribute to the risk of falls among elderly patients; the extent of this contribution alone is apparently not great, but merits consideration, together with other factors affecting the individual patient, in calculating the risks versus the benefits of prescribing these drugs.

While some earlier studies had demonstrated that benzodiazepines impair recall in elderly subjects, recent studies have appropriately sought to determine whether elderly subjects are in fact more sensitive to this effect than younger subjects. Testing of different age groups prior to drug administration, or under placebo conditions, demonstrates that recall abilities decline with age. Administration of benzodiazepines produces further decrements in recall in elderly subjects, but these are no greater proportionally than those produced in younger subjects (Hinrichs and Ghoneim 1987; Pomara et al. 1989; Greenblatt et al. 1991). However, because of the baseline deficits in recall in the elderly, the additional impairment produced by benzodiazepines may represent a more severe compromise.

\section{Triazolam}

Not long after triazolam was marketed, it was banned in the Netherlands in 1979 as a result of widely-publicized case reports of adverse behavioral effects. In 1991, the drug - which had become the most frequently prescribed hypnotic - was banned in the UK, and then banned or severely restricted in other Western European nations. The US Food and Drug Administration also reviewed the safety of triazolam in 1991, and concluded only that stricter limits for use should be recommended in labelling. These recent actions too were taken largely on the basis of case reports of untoward behavioral effects, which have by now appeared in record numbers. Regardless of their numbers, however, case reports cannot serve to establish whether clinical phenomena can be attributed to drug use. Neither can they serve to estimate the incidence of possible drug reactions, since it is not clear how these may relate to the extent of use of the drug. In short, to address these questions meaningfully, case reports cannot substitute for controlled studies.

Very few controlled studies have inquired into the incidence or nature of daytime distress during and after periods of nightly administration of triazolam. Some studies found certain adverse effects during and/or after treatment, including increased anxiety (Morgan and Oswald 1982; Kales et al. 1983) and apparent idiosyn- cratic reactions such as panic attacks, personality changes, and delusional episodes (Adam and Oswald 1989); others have found no increased anxiety (Roth et al. 1976; Mamelak et al. 1984; Bliwise et al. 1988) or hostility (Roth et al. 1976) during triazolam treatment or upon discontinuation. Further controlled research is certainly needed to establish whether triazolam and/or other short-acting benzodiazepines canproduce such adverse effects, and if so what their nature and incidence might be.

\section{Restriction of benzodiazepine use}

Concerns about benzodiazepine use have led to various initiatives to restrict this use, both at the public health and clinical levels. In the last few years, some evidence has begun to emerge regarding the effects of such interventions. This information about the consequences of reducing or eliminating the availability of these drugs provides an important new perspective on the global significance of the use of benzodiazepines, and indeed of psychotherapeutic drugs in general.

\section{Government regulation}

From a scientific viewpoint, as described previously, it has been shown that it is inappropriate to regard benzodiazepines in the traditional context of "drugs of abuse." Needless to say, however, this perspective lingers in some quarters, and continues to affect public policy decisions. The danger of this misperception is illustrated by a regulation imposed in New York State in 1989 because of the significant "public health danger posed by benzodiazepine abuse and misuse...." (Eadie 1990). The regulation stipulated, among other things, that benzodiazepine prescriptions can be issued only on the State's triplicate-copy prescription forms, of which one copy is forwarded to the State Department of Health for computerized monitoring.

The effect of this regulation, in the year following its implementation, was that benzodiazepine prescriptions in the state declined by about half. At the same time, prescriptions substantially increased for a number of nonbenzodiazepine drugs, which physicians apparently prescribed as substitutes for benzodiazepines, e.g., meprobamate, barbiturates, and other sedative-hypnotics that are "older, less effective, and more hazardous" (Shader et al. 1991) than benzodiazepines. However, the increase in prescriptions for substitute drugs was not sufficient to offset the reduction in benzodiazepine prescriptions; thus another effect of the regulation may have been to exacerbate the longstanding problem of under treatment of anxiety and insomnia (Reidenberg 1991; Shader et al. 1991; Weintraub et al. 1991).

In ten nursing homes in western New York State, $70 \%$ of patients who had been receiving 
benzodiazepines were discontinued when the regulation went into effect. Most were switched to other psychoactive medications; for those who had been receiving benzodiazepine anxiolytics, the most frequent substitute was a neuroleptic, while the most frequent substitutes for benzodiazepine hypnotics were chloral hydrate and diphenhydramine (Zullich et al. 1992).

In the 3 months after the regulation became effective, of the presentations at a New York City emergency room for problems associated with benzodiazepine use, half were clearly or probably related to the new regulation; most of these involved either frank withdrawal syndromes or re-emergence of anxiety disorders that had previously been controlled by benzodiazepine treatment (Schwartz and Blank 1991). In the year following implementation of the regulation, benzodiazepine overdoses in New York City significantly declined, whereas overdoses of other sedative-hypnotic drugs significantly increased; there was no overall change in the number of sedative-hypnotic overdoses (Hoffman et al. 1991).

\section{Clinical programs to discontinue long-term use}

Some psychiatric and other facilities have offered programs for supervised discontinuation of long-term use of benzodiazepines. A number of recent studies have examined the outcomes of patients who participated in such programs. The great majority of patients who seek to end long-term use can achieve discontinuation (Rickels et al. 1986; Ashton 1987; Golombok et al. 1987; Holton and Tyrer 1990), though some may require inpatient treatment to do so (Joughin et al. 1991). Of those who successfully discontinue benzodiazepine use, many patients experience clinical improvement in the short term (Cantopher et al.1990; Rickels et al. 1990; Schweizer et al. 1990). There is some evidence that those who remain abstinent for long periods continue to do well (Rickels et al. 1991; Schwartz and Blank 1991), but the corollary interpretation is that those who do not do well resume treatment. Most studies find that, within about a year after discontinuing long-term benzodiazepine treatment, half to two thirds of patients have experienced relapse of their original symptoms (Higgitt et al. 1985; Rickels et al. 1986; Golombok et al. 1987); and about half of these patients have resumed benzodiazepine use (Higgitt et al. 1985; Rickels et al. 1986; Priebe et al. 1988; Cantopher et al. 1990 ). Studies that have followed patients for longer periods after discontinuation, i.e. 3-6 years, find that the majority of patients have resumed benzodiazepine use for some period or are still taking them (Holton and Tyrer 1990; Rickels et al. 1991).

In addition to providing these rough estimates of the results of discontinuing long-term benzodiazepine use, these studies raise basic questions about the objectives of discontinuation. Should abstinence per se be the sole or primary criterion of "success?" In one study of discontinuation of chronic benzodiazepine use, 14 of 21 patients remained abstinent after 6 months. Based on ratings of clinical status, however, four of these patients had a "poor" outcome, of whom three had required psychiatric hospitalization; two other patients committed suicide, at 4 and 14 months after discontinuation of benzodiazepine treatment (Joughin et al. 1991).

\section{Comment}

Since benzodiazepines act as CNS depressants, it was originally assumed that these drugs would share the high liability for abuse traditionally associated with sedative-hypnotics. Three decades of extensive experimental, clinical, and epidemiological experience have shown that this assumption was erroneous; benzodiazepines have little liability for abuse in the general population or typical patient populations.

Benzodiazepines can produce physiological dependence. This dependence does not appear to be associated with psychological dependence or "addiction," which might be accompanied by inappropriate and possibly harmful drug-seeking and -taking behaviors, such as escalation of doses. On the contrary, there is no persuasive evidence of harm associated with physiological dependence on benzodiazepines, apart from the discomfort of withdrawal upon discontinuation. Withdrawal may be more intense following discontinuation of the short-acting than of the longer-acting agents. In any case, withdrawal distress can be minimized by gradual tapering of dosage.

A substantial number of patients who receive prescriptions for benzodiazepines continue to use these drugs for long periods. While we have an immense body of knowledge about many of the effects of benzodiazepines, we have very little information about either the benefits or the risks of long-term use. The standard instruments for evaluation of the effects of anxiolytics and hypnotics in humans were designed to examine relatively short periods of treatment; new approaches may be required to examine effects of long-term use.

Most people afflicted by anxiety or insomnia go without treatment (Consensus Conference 1984; Mellinger et al. 1984b). This represents a great deal of suffering, much of it probably unnecessary; and there is evidence linking untreated anxiety with increased risks of depression (Lesser et al. 1988), alcoholism (Regis et al. 1988), suicide (Fawcett 1988), and death due to unnatural causes (Coryell et al. 1982). Benzodiazepines currently represent the best treatments available for anxiety and insomnia. It is important to ensure the availability of these drugs for their intended therapeutic purposes. Initiatives that might restrict this availability should be undertaken only if they can be shown likely to produce benefits greater 
than their risks (Woods 1990). As demonstrated by the experience in New York State, increased restriction of the overall availability of benzodiazepines poses serious dangers to the public health. This regulation led physicians to prescribe less effective and more hazardous drugs for some patients, and to leave others without treatment of any kind.

Similarly, the decision to continue or discontinue benzodiazepine treatment in chronic users should weigh the possible risks of discontinuation against the possible benefits. The available evidence indicates that, while some chronic users may no longer need medication and may in fact improve after discontinuation, others experience relapse of their original disorders and can benefit from continued benzodiazepine therapy. This benefit/risk calculation, like the decision to prescribe these drugs in the first place, must be made by the physician on the basis of the circumstances affecting the individual patient.

\section{References}

Adam K, Oswald I (1989) Can a rapidly-eliminated hypnotic cause daytime anxiety? Pharmacopsychiatry $22: 115-119$

Antonijoan RM, Barbanoj MJ, Torrent J, Jane F (1990) Evaluation of psychotropic drug consumption related to psychological distress in the elderly: hospitalized vs. nonhospitalized. Neuropsychobiology $23: 25-30$

Ashton H (1987) Benzodiazepine withdrawal outcome in 50 patients. Br J Addict $82: 665-672$

Balter MB (1991) Prevalence of medical use of prescription drugs. Presented at NIDA technical review, evaluation of the impact of prescription drug diversion control systems on medical practice and patient care: possible implications for future research, Bethesda, Md.

Bellantuono C, Arreghini E, Adarni M, Bodini F, Gastaldo M, Micciolo R (1989) Psychotropic drug prescription in Italy: a survey in general practice. Soc Psychiatry Psychiatr Epidemiol 24 $212-218$

Bliwise DL, Seidel WF, Cohen SA, Bliwise NG, Dement WC (1988) Profile of Mood States changes during and after 5 weeks of nightly triazolam administration. J Clin Psychiatry 49 : 349-355

Busto U, Sellers EM, Naranjo CA, Cappell H, Sanchez-Craig M, Sykora K (1986) Withdrawal reaction after long-term therapeutic use of benzodiazepines. N Engl J Med 315:854-859

Cantopher T, Olivieri S, Cleave N, Edwards JG (1990) Chronic benzodiazepine dependence: a comparative study of abrupt withdrawal under propranolol cover versus gradual withdrawal. $\mathrm{Br}$ J Psychiatry 156:406-411

Cappell H, Busto U, Kay G, Naranjo CA, Sellers EM, SanchezCraig M (1987) Drug deprivation and reinforcement by diazepam in a dependent population. Psychopharmacology 91 : $154-160$

Consensus conference (1984) Drugs and insomnia: the use of medications to promote sleep. JAMA $351: 2410-2414$

Coryell W, Noyes $R$, Clancy $J$ (1982) Excess mortality in panic disorder: a comparison with primary unipolar depression. Arch Gen Psychiatry $39: 701-703$

Cumming RG, Miller JP, Kelsey JL, Davis P, Arfken CL, Birge SJ and Peck WA (1991) Medications and multiple falls in elderly people:the St. Louis OASIS Study. Age Ageing 20:455-461

DeWit H, Pierri J, Johanson CE (1989) Reinforcing and subjective effects of diazepam in nondrug-abusing volunteers. Pharmacol Biochem Behav 33:205-213
Eadie JL (1990) Policy concerns: benzodiazepine abuse and misuse: New York state's response. In: Wilford BB (ed) Balancing the response to prescription drug abuse. American Medical Association, Chicago, Ill., pp 93-102

Fawcett J (1988) Predictors of early suicide: identification and appropriate intervention. $\boldsymbol{J}$ Clin Psychiatry 49 [suppl] : 7-8

Fichter MM, Witzke W, Leibl K, Hippius H (1989) Psychotropic drug use in a representative community sample: the Upper Bavarian West Germany study. Acta Psychiatr Scand 80:68-77

Fyer AJ, Liebowitz MR, Gorman JM, Campeas R, Levin A, Davies SO, Goetz D and Klein DF (1987) Discontinuation of alprazolam treatment in panic patients. Am J Psychiatry $144: 303-308$

Gallager DW, Heninger K, Heninger G (1986) Periodic benzodiazepine antagonist administration prevents benzodiazepine withdrawal symptoms in primates. Eur J Pharmacol $132: 31-38$

Geneé-Badia J, Blay-Pueyo C, Soler-Vila M (1988) Risk factors in the use of benzodiazepines. Fam Pract. 5:283 288

Golenpaul D (1991) The 1991 Information Please Almanac, 15th Ed, Boston, MA: Houghton Mifflin, 1991: 141

Golombok S, Higgitt A, Fonagy P, Dodds S, Saper J, Lader M (1987) A follow-up study of patients treated for benzodiazepine dependence. Br J Med Psychol $60: 141-150$

Greenblatt DJ, Shade RI, Harmatz JS (1989) Implications of altered drug disposition in the elderly: studies of benzodiazepines. J Clin Pharmacology $29: 866-872$

Greenblatt DJ, Jerold SH, Shapiro L, Engelhardt N, Gouthro TA, Shader RI (1991) Sensitivity to triazolam in the elderly. N Engl J Med $324: 1691-1698$

Grisso JA, Kelsey JL, Strom BL, Chiu GY, Maislin G, O'Brien LA, Hoffman S, Kaplan F (1991) Risk factors for falls as a cause of hip fracture in women. $N$ Engl $J$ Med 324 : 1326-1331

Gurwitz JH, Avorn J (1991) The ambiguous relation between aging and adverse drug reactions. Ann Int Medicine 114:956-966

Hale WE, Stewart RB, Marks RG (1985) Anti-anxiety drugs and central nervous system symptoms in an ambulatory elderly population. DICP $19: 37-40$

Haskell D, Cole JO, Schniebolk S, Lieberman B (1986) A survey of diazepam patients. Psychopharmacol Bull $22: 434-438$

Higgitt AC, Lader MH, Fonagy P (1985) Clinical management of benzodiazepine dependence. BMJ $291: 688-690$

Hinrichs JV, Ghoneim MM (1987) Diazepam, behavior, and aging: increased sensitivity or lower baseline performance? Psychopharmacology 92:100-105

Hoffman RS, Wipfler JG, Maddaloni MA, Weisman RS (1991) Has the New York State triplicate benzodiazepine prescription regulation influenced sedative-hypnotic overdoses? N Y State J Med $91: 436-439$

Holton A, Tyrer P (1990) Five year outcome in patients withdrawn from long term treatment with diazepam. BMJ 300: 1241-1242

Johnston LD, O'Malley PM, Bachman JG (1993a) National Survey Results on Drug Use from the Monitoring the Future Study, 1975-1992: Volume I: Secondary School Students. NIH Publication No. 93-3597. Washington: U.S. Government Printing Office

Johnston LD, O'Malley PM, Bachman JG (1993b) National Survey Results on Drug Use from the Monitoring the Future Study, 1975-1992: Volume II: Secondary School Students. NIH Publication No. 93-3598. Washington: U.S. Government Printing Office

Joughin N, Tata P, Collins M, Hooper C, Falkowski J (1991) Impatient withdrawal from long-term benzodiazepine use. $\mathrm{Br} \mathrm{J}$ Addict $86: 449-455$

IMS America Ltd. National Disease and Therapeutic Index (NDTI), Plymouth Meeting, PA: IMS America, Ltd; 1991

Kales A, Soldatos CR, Bixler EO, Kales JD (1983) Early morning insomnia with rapidly eliminated benzodiazepines. Science 220:95-97

Lesser IM, Rubin RT, Pecknold JC, Rifkin A, Swinson RP, Lydiard RB, Burrows GD, Noyes R, Dupont RL (1988) Secondary depression in panic disorder and agoraphobia. I. Frequency, 
severity, and response to treatment. Arch Gen Psychiatry $45: 437-443$

Lucki I, Rickels K (1988) The effect of anxiolytic drugs on memory in anxious subjects. Psychopharmacol Ser 6:128-139

Lucki I, Volpicelli JR, Schweizer E (1991) Differential craving between abstinent alcohol-dependent subjects and therapeutic users of benzodiazepines. NIDA Res Monogr 105:322-323

Magni G, Schifano F, Pastorello M, Deleo D, DeDominicis MG (1986) Use of psychotropic drugs in general, medical geriatric inpatients: relationship with various parameters of psychological distress evluated in blind. Neuropsychobiology. 16:181-185

Mamelak M, Csima A, Price V (1984) A comparative 25-night sleep laboratory study on the effects of quazepam and triazolam on chronic insomniacs. J Clin Pharmacol $24: 65-75$

Mellinger GD, Balter MB, Manheimer DI, Cisin IH, Parry HJ (1978) Psychic distress, life crisis, and use of psychotherapeutic medications: National Household Survey data. Arch Gen Psychiatry $35: 1045$

Mellinger GD, Balter MB, Uhlenhuth EH (1984a) Anti-anxiety agents: duration of use and characteristics of users in the U.S.A. Curr Med Res Opin 8 (suppl. 4) :21-36

Mellinger GD, Balter MB, Uhlenhuth EH (1984b) Prevalence and correlates of the long term regular use of anxiolytics. JAMA $331: 375-379$

Mellman TA, Uhde TW (1986) Withdrawal syndrome with gradual tapering of alprazolam. Am J Psychiatry 143:1464-1466

Morgan K, Oswald I (1982) Anxiety caused by a short-life hypnotic. Br Med J 284:942

Murphy SM, Owen R, Tyrer P (1989) Comparative assessment of efficacy and withdrawal symptoms after 6 and 12 weeks' treatment with diazepam or buspirone. Br J Psychiatry 154:529 534

Myers AH, Baker SP, Van Natta $M L$, Abbey $H$, Robinson EG (1991) Risk factors associated with falls and injuries among elderly institutionalized persons. Am $\mathbf{J}$ Epidemiol 133: 1179-1190

Noyes R, Garvey MJ, Cook B, Suelzer M (1991) Controlled discontinuation of benzodiazepine treatment for patients with panic disorder. Am J Psychiatry 148: 517-523

Orsini A, Brancato V, Smeraldi E (1990) Length of anxiolytic treatment and benzodiazepine withdrawal symptoms: a double blind study with clotiazepam. New Trends Exp Clin Psychiatry $6: 45-52$

Oster G, Russell MW, Huse DM, Adams SF, Imbimbo J (1987) Accident and injury related health care utilization among benzodiazepine users and nonusers. J Clin Psychiatry 48:17-21

Oster G, Huse DM, Adams SF, Imbimbo J, Russell MW (1990) Benzodiazepine tranquilizers and the risk of accidental injury. Am J Public Health 80:1467-1470

Pakesch G, Loimer N, Rasinger E, Tutsch G, Katschnig H (1989) The prevalence of psychoactive drug intake in a metropolitan population. Pharmacopsychiatry $2: 61-65$

Pecknold JC, Swinson RP, Kuch K, Lewis CP (1988) Alprazolam in panic disorder and agoraphobia: results from a multicenter trial. III. Discontinuation effects. Arch Gen Psychiatry $45: 429-436$

Pomara N, Deptula D, Medel M, Block RI, Greenblatt DJ (1989) Effects of diazepam on recall memory: relationship to aging, dose, and duration of treatment. Psychopharmacol Bull $25: 144-148$

Priebe S, Liesenfeld O, Muller-Oerlinghausen B (1988) Resumption of benzodiazepine use after withdrawal in hospital - a followup study. Pharmacopsychiatry $21: 353-354$

Ray WA, Griffin MR, Schaffner W, Baugh DK, Melton LJ (1987) Psychotropic drug use and the risk of hip fracture. N Engl J Med 316:363-369

Ray WA, Griffin MR, Downey W (1989) Benzodiazepines of long and short elimination half-life and the risk of hip fracture. JAMA $262: 3303-3307$

Ray, WA (1992) Psychotropic drugs and injuries among the elderly: a review. J Clin Psychopharmacology 12:386-396
Regis DA, Boyd JH, Burke JD, Rae DS, Myers JK, Kramer M, Robins LN, George LK, Karno M and Lock BZ (1988) Onemonth prevalence of mental disorders in the United States: based on five epidemiologic catchment area sites. Arch Gen Psychiatry 45: $977-986$

Reidenburg MM (1991) Effect of the requirement for triplicate prescriptions for benzodiazepines in New York State. Clin Pharmacol Ther 50:129-131

Rickels K, Case WG, Schweizer EE, Swenson C, Fridman RB (1986) Low-dose dependence in chronic benzodiazepine users: a preliminary report of 119 patients. Psychopharmacol Bull $22: 407$

Rickels K, Fox IL, Greenblatt DJ, Sandler KR, Schless A (1988) Clorazepate and lorazepam: clinical improvement and rebound anxiety. Am J Psychiatry 145:312-317

Rickels K, Schweizer E, Cse WG, Greenblatt DJ (1990) Long-term therapeutic use of benzodiazepines. I. Effects of abrupt discontinuation. Arch Gen Psychiatry 47:899-907

Rickels K, Case W, Schweizer E, Garcia-Espana F, Fridman R (1991) Long-term benzodiazepine users 3 years after participation in a discontinuation program. An J Psychiatry $148: 757-761$

Ried LD, Christensen DB, Stergachis A (1990) Medical and psychosocial factors predictive of psychotropic drug use in elderly patients. Am J Public Health 80:1349-1353

Roth T, Kramer M, Lutz T (1976) Intermediate use of triazolam: a sleep laboratory study. J Int Med Res $4: 59-63$

Salinsky JV, Dore CJ (1987) Characteristics of long term benzodiazepine users in general practice. J R Coll Gen Pract 37 : 202-204

Schwartz HI, Blank K (1991) Regulation of benzodiazepine prescribing practices: clinical implications. Gen Hosp Psychiatry $13: 219-224$

Schweizer E, Case WE, Rickels K (1989) Benzodiazepine dependence and withdrawal in elderly patients. Am J Psychiatry $146: 529-531$

Schweizer E, Rickels K, Case WG, Greenblatt DJ (1990) Long term therapeutic use of benzodiazepines. II. Effects of gradual taper. Arch Gen Psychiatry 47:908-915

Shader RI, Greenblatt DJ, Balter MB (1991) Appropriate use and regulatory control of benzodiazepines. J Clin Pharmaco $31: 781-784$

Sobel KG, McCart GM (1983) Drug use and accidental falls in an intermediate care facility. DICP $17: 539-542$

Sorock GS, Shimkin EE (1988) Benzodiazepine sedatives and the risk of falling in a community-dwelling elderly cohort. Arch Intern Med 148:2441-2444

Substance Abuse and Mental Health Services Administration (1993) National Household Survey on Drug Abuse: Main Findings 1991. Revised November 20, 1992. DHHS Publication No. (SMA) 93-1980. Washington: U.S. Government Printing Office

Substance Abuse and Mental Health Services Administration (1993) National Household Survey on Drug Abuse: Population Estimates 1992. DHHS Publication No. (SMA) 93-2053. Washington: U.S. Government Printing Office

Swartz M, Landerman R, George LK, Melviller ML, Blazer D, Smith K (1991) Benzodiazepine anti-anxiety agents: prevalence and correlates of use in a southern community. Am J Public Health. $81: 592-596$

Trewin VF, Lawrence CJ, Veitch GB (1992) An investigation of the association of benzodiazepines and other hypnotics with the incidence of falls in the elderly. J Clin Pharm Ther $17: 129-133$

Vazquez-Barquero JL, Diez-Manrique JF, Pena C, ArenalGonzalez A, Cuesta MJ, Artal JA (1989) Patterns of psychotropic drug use in a Spanish rural community. Br J Psychiatry $155: 633-641$

Weintraub M, Singh S, Byrne L, Maharaj K, Guttmacher L (1991) Consequences of the 1989 New York State triplicate benzodiazepine prescription regulations. JAMA 266:2392-2433 
Wells BG, Middleton B, Lawrence G, Lillard D, Safarik J (1985) Factors associated with the elderly falling in intermediate care facilities. DICP 19:142-145

Woods JH, Katz JL, Winger G (1987) Abuse liability of benzodiazepines. Pharmacol Rev. 39:251-419

Woods JH, Katz JL, Winger G (1988) Use and abuse of benzodiazepines: issues relevant to prescribing. JAMA $26: 3476-3480$

Woods JH (1990) Abuse liability and the regulatory control of therapeutic drugs: untested assumptions. Drug Alcohol Depend $25: 229-233$
Woods JH, Katz JL, Winger G (1992) Benzodiazepines: use, abuse, and consequences. Pharmacol Rev $44: 151-347$

Zullich SG, Grasela TH, Fieldler-Kelly JB, Gengo FM (1992) Impact of triplicate prescription program on psychotropic prescribing patterns in long-term care facilities. Annals of Pharmacotherapy $26: 539-546$ 